OMEGA, Vol. 56(4) 331-348, 2007-2008

\title{
PROBLEMATIC EMOTIONS AND MATERNAL GRIEF
}

\author{
PETER BARR \\ Royal Alexandra Hospital for Children, Sydney, Australia \\ JOANNE CACCIATORE \\ Arizona State University, Phoenix
}

\begin{abstract}
The study was an empirical examination of the relation of personality proneness to "problematic social emotions"-envy (Dispositional Envy Scale), jealousy (Interpersonal Jealousy Scale), and shame and guilt (Personal Feelings Questionnaire-2) - to maternal grief (Perinatal Grief Scale-33) following miscarriage, stillbirth, neonatal death, or infant/child death. The 441 women who participated in the study were enrolled from the Website, e-mail contact lists, and parent support groups of an organization that offers information and support to bereaved parents. All four problematic emotions were positively correlated with maternal grief. Envy, jealousy, and guilt made significant unique contributions to the variance in maternal grief. Overall, time lapse since the loss and the four problematic emotion predispositions explained $43 \%$ of the variance in maternal grief following child bereavement.
\end{abstract}

Mothers' narrative accounts of grief following miscarriage, stillbirth, neonatal death, or infant/child death indicate they may be deeply troubled by what have been referred to as the "problematic social emotions" (Tangney \& Salovey, 1999), namely shame, guilt, envy, and jealousy (Borg \& Lasker, 1989; Kohner \& Henley, 2001). However, the following first-person accounts cited by Borg and

(c) 2008, Baywood Publishing Co., Inc.

doi: 10.2190/OM.56.4.b

http://baywood.com 
Lasker (1989) and Kohner and Henley (2001), suggest that grieving mothers may not be aware that one or more problematic emotion may be informing their grief.

I lost all sense of worth, felt useless and had no confidence in anything I did. Most of all, I now know, I never felt worthy of giving myself any praise. I felt a failure, and I tried to carry on as normal to compensate for failing everyone else (Kohner \& Henley, 2001, p. 74).

The sense of worthlessness and powerlessness and the global devaluation of the self ("I felt a failure") expressed by this grieving mother are typical manifestations of shame (Lewis, 1971; Nathanson, 1987; Tangney, 1995). Although the mother may have been aware of her underlying shame feelings, the aversive nature of the emotion and the reluctance to admit shame's presence (Retzinger, 1995) posit the possibility she or others may have concluded she suffered from low self-esteem and depression without realizing that "shame is the affectivecognitive state of low self-esteem" (Lewis, 1987, p. 39).

I thought I was being punished, that I had caused her to be born early because I had a cold and was constantly coughing. I felt totally useless and unneeded and convinced that I was a terrible mother (Borg \& Lasker, 1989, p. 74).

In this statement, the grieving mother of a premature infant who died in the newborn period portrayed the hallmarks of chronic self-reviling guilt-a disproportionate and/or irrational responsibility for an imagined transgression, accompanied by a morbid fear of punishment (Bybee \& Quiles, 1998; Cullberg, 1971; Freud, 1961/1930; Harder, 1995; Kugler \& Jones, 1992). Although the mother was probably aware of feeling guilty about something she did ("constantly coughing") that in her mind caused the premature birth and subsequent death, she or others may not have appreciated her shame-related characterological self-blame ("I was a terrible mother"), which often accompanies and aggravates guilt-related behavioral self-blame (Janoff-Bulman, 1979; Lewis, 1971; Tangney, Burggraf, \& Wagner, 1995; Weiner, 1986) and may be more responsible than guilt for psychological symptoms (Bybee \& Quiles, 1998; Harder, 1995; Tangney \& Dearing, 2002).

There are mothers who drink, smoke and take drugs in their pregnancies but they still have healthy babies that survive. Then there are women like me. I didn't smoke, drink or take drugs in my pregnancy, I watched my diet and I took care of myself, and look what happened. Life's just so unfair (Kohner \& Henley, 2001, p. 76).

In the preceding reflection, the grieving mother's belief that she had been treated unjustly called forth her moral indignation, bitterness, and resentment. However, she did not use the word envy and she may not have understood or been prepared to acknowledge that she was perhaps envious of women who, in her estimation, were less deserving in a life domain that was profoundly important to 
her own sense of self (Anderson, 2002; Furman, 1996; Smith, 1991; Smith, Parrott, Diener, Hoyle, \& Kim, 1999).

When I wake up, sympathetic faces walk past me, but . . . they will never understand what I feel. It was a girl, they say. She should have lived, but . . . she is dead. It's an 'accident.' No. . . . For me, it's failure, And jealousy. . . . Why all the others and not me (Borg \& Lasker, 1989, p. 13)?

Although the mother in this last narrative reported that she was jealous, her sense of injustice ("Why all the others and not me?") is more typical of envy (Parrott \& Smith, 1993), which according to the Oxford English Dictionary is a "feeling of discontented or resentful longing aroused by someone else's possessions, qualities, or luck," rather than jealousy, which the dictionary defines as "the consuming fear, suspicion, or belief that one is being or might be displaced in someone's affections" (Salovey, 1991). In fact, individuals frequently use the word jealous(y) to describe the experience of envy and ordinarily one would not expect an association between jealousy, as previously defined, and maternal grief, since there is no apparent rival for the deceased child's affections (Smith, Kim, \& Parrott, 1988). On the other hand, grieving mothers may be vulnerable to the jealousy that may accompany the threat of loss occasioned by "high family boundary ambiguity" (Boss \& Greenberg, 1984). In other words, if the grieving mother experiences her dead child as being psychologically present but physically absent and/or her husband or partner as being physically present but psychologically absent, she becomes vulnerable to the threat of loss occasioned by this ambiguity and she may describe the experience in terms of jealousy (Hansen, 1991).

Negative emotions exist along a continuum from emotion states through moods to emotion-based personality predispositions (Malatesta \& Wilson, 1988), and maladaptive personality traits based on shame, guilt, envy, or jealousy have been shown to bias cognition and subsequent behavior in ways that denigrate the self, disrupt social relationships, and promote various forms of psychopathology (Bybee \& Quiles, 1998; Ekman \& Davidson, 1994; Farber, 1976a, 1976b; Harder, 1995; Lazarus \& Lazarus, 1994; Neu, 1980; Smith et al., 1999; Sullivan, 1953; Tangney et al., 1995; Tangney \& Salovey, 1999). If Bonanno (2001) is correct and "recovery [from bereavement] is most likely to occur when negative griefrelated emotions are regulated or minimized" (p. 493), then dysregulated personality traits based on one or more problematic emotions should have important relationships with maternal grief. In support of this claim, previous research has shown that personality guilt- and shame-proneness explain a substantial proportion of the variance in maternal grief following perinatal bereavement (Barr, 2004).

The relationship of dispositional envy and jealousy to maternal grief has not been studied; however, the psychological properties that these emotions share with shame and guilt, including negative valence, threat to the integrity of the self, 
perceived inferiority in relevant interpersonal domains, and destructive patterns of social interaction (Anderson, 2002; Berke, 1987; Tangney \& Salovey, 1999), suggest that proneness to envy and, less certainly, proneness to jealousy may have important relationships with maternal grief. Although difficult to access in counseling because of their strongly aversive character, the recognition of grief-related problematic emotions may be important because each member of the constellation may be amenable to psychotherapeutic intervention (Anderson, 2002; Greenberg \& Paivio, 1993; Harder \& Greenwald, 2000; Raphael, Minkov, \& Dobson, 2001). Thus, the purpose of the present study was to empirically examine the hypothesis that predispositional envy, jealousy, shame, and guilt are related to each other and to maternal grief following miscarriage, stillbirth, neonatal death, or infant/child death.

\section{METHODS}

\section{Procedure}

The study protocol was published on the Mothers in Sympathy and Support (M.I.S.S.) Foundation Website from March 2005 through August 2006. Foundation members and affiliates were notified of the study through Internet links, e-mail lists, parent support groups, and other bereaved parent organizations. The study questionnaires could be completed online or downloaded, completed and mailed to the Foundation for online data entry. The data from the HTML Web form were saved to a MySQL database on an Apache Web server (Birnbaum, 2004).

Prospective participants were invited to take part in a study whose stated intention was to understand the relation between "present thoughts and feelings about your loss" (grief) and "feelings of longing and unfairness" (envy), "personal feelings" (shame and guilt), and "security in relationship" (jealousy) following bereavement from miscarriage, stillbirth, newborn death or infant/ child death-hereafter referred to as child death or bereavement. The study was anonymous and no information was collected that might have identified participants. The study involved no more than minimal-risk to participants' well-being and their voluntary participation was considered to represent informed consent.

The participants were asked to provide demographic information concerning their sex, age, ethnicity, education, relationship status, and child bereavement history. Thereafter in order, they completed self-report questionnaire measures of grief (Perinatal Grief Scale (PGS-33); Potvin, Lasker, \& Toedter, 1989), envy (Dispositional Envy Scale (DES); Smith et al., 1999), shame and guilt (Personal Feelings Questionnaire-2 (PFQ-2); Harder \& Zalma, 1990), and jealousy (Interpersonal Jealousy Scale (IJS); Mathes \& Severa, 1981). 


\section{Participants}

The PGS-33 was completed by 612 respondents, but only 464 of these completed the DES, PFQ-2, and IJS. The 441 women respondents who completed all four questionnaires comprise the study population. The study women were not statistically significantly different from the women who only completed the PGS-33 with respect to their grief scores and the above-mentioned demographic variables.

The women were aged from 19 to 54 years $(M=32.5, S D=6.87)$. They reported their ethnic origin as European-American (70.5\%), African-American (1.8\%), Native-American (2.5\%), Asian-American (0.7\%), Hispanic (3.4\%), and Other (non-American, 21.1\%). The women reported their level of education as Year 11 or earlier $(6.1 \%)$, high school diploma $(28.3 \%)$, associate degree or certificate $(22.0 \%)$, bachelor's degree $(28.3 \%)$, master's degree $(10.2 \%)$, and $\mathrm{Ph} . \mathrm{D}$. or advanced professional degree (5.0\%). They described their relationship status as married or cohabiting $(90.2 \%)$, single $(4.5 \%)$, separated $(1.8 \%)$, and divorced (3.4\%).

Although a history of more than one child bereavement was common, the time lapse since the most recent death (TRD) was the independent variable used in the statistical analyses (Lasker \& Toedter, 2000). The most recent category of death with the total number of child deaths for the category in parentheses was reported as miscarriage 67 (119), stillbirth 194 (489), neonatal death 78 (153), and infant or child death 102 (216). The median TRD was 8 months (range 0-343 months).

\section{Measures}

\section{Perinatal Grief Scale-33}

The intensity of maternal grief was measured with the PGS-33 (Potvin et al., 1989), which is a psychometrically valid and reliable 33-item self-report questionnaire with three factor-analyzed 11-item subscales referred to as Active Grief, Difficulty Coping and Despair (Toedter, Lasker, \& Alhadeff, 1988; Toedter, Lasker, \& Janssen, 2001). The Active Grief subscale contains items that reflect anguish over the death of a baby, such as, "I feel empty inside." The Difficulty Coping subscale contains items that signify social withdrawal, difficulty with normal everyday life activities and depression, such as, "I find it difficult to make decisions since the baby died." The Despair subscale contains items concerned with existential feelings of helplessness and hopelessness, such as, "I try to laugh, but nothing seems funny anymore." The questionnaire items are presented as statements to which participants respond on a 5 -point Likert scale that ranges from 1 "Strongly agree" to 5 "Strongly disagree" with a neutral midpoint. Thirty-one of the 33 items are negatively valenced and these scores are reversed before summing the individual item scores to obtain 
the total and subscale scores such that higher scores indicate more intense grief. Only the total PGS-33 score was used in the present study.

Women who had experienced the death of a child beyond the neonatal period were included in the study and in order to accommodate this group the PGS-33 was modified with the permission of the scale's authors and the word "baby" in the item statements replaced with the compound word "baby/child." The internal reliability coefficient (Cronbach's $\alpha$ ) for the PGS-33 was .94 for the entire study population and for the subgroup of women who reported the death of a child beyond the neonatal period.

Dispositional Envy Scale

Women's proneness to envy was measured with the DES (Smith et al., 1999), which is a psychometrically valid and reliable 8-item self-report questionnaire that captures the theoretically important characteristics of envy, namely

1. feelings of inferiority, such as, "The bitter truth is that I generally feel inferior to others";

2. feeling frustrated, such as, "It is so frustrating to see some people succeed so easily";

3. subjective injustice, such as, "It somehow doesn't seem fair that some people seem to have all the talent"; and

4. the frequency and intensity of envious feelings, such as, "No matter what I do, envy always plagues me."

The items are presented as statements to which participants respond on a 5-point Likert scale that ranges from 1 "Strongly disagree" to 5 "Strongly agree" with a neutral midpoint. The Cronbach's $\alpha$ value for the DES was .90 .

\section{Personal Feelings Questionnaire-2}

The PFQ-2 was used to measure women's chronic shame- and guilt-proneness (Harder \& Zalma, 1990). The PFQ-2 is a psychometrically valid and reliable self-report questionnaire with factor-analyzed shame ( 10 items) and guilt (6 items) scales (Harder \& Zalma, 1990). The shame-relevant and guilt-relevant words or phrases used in the PFQ-2 were chosen for their distinguishing affective, cognitive, and phenomenological characteristics (Harder \& Lewis, 1987; Lewis, 1971). The shame items include "feeling ridiculous" and "feeling humiliated," whereas those pertaining to guilt include "mild guilt," "remorse," and "regret." Participants are presented with an emotion word or phrase and asked how frequently they experience the feeling on a 5-point Likert scale that ranges from 0 "Never experience" to 4 "Continuously or almost continuously experience" without a neutral midpoint. The individual shame and guilt item scores are 
summed to give total scores for chronic shame- and guilt-proneness. The respective Cronbach's $\alpha$ values for PFQ-2 Shame and Guilt were .83 and .80 .

Interpersonal Jealousy Scale

The women's proneness to jealousy was measured with the IJS (Mathes \& Severa, 1981), which is a psychometrically valid and reliable 28-item single factor self-report questionnaire measure of jealousy, defined as the "negative emotion resulting from actual or threatened loss of love to a rival" (Mathes \& Severa, 1981, p. 24). The IJS measures "romantic" relationship jealousy in the following domains:

1. infidelity, such as, "The thought of my partner kissing someone else drives me up the wall";

2. popularity, such as, "If someone of the opposite sex lit up at the sight of my partner, I would become uneasy";

3. untrustworthiness, such as, "If my partner were to become very close to someone of the opposite sex, I would feel very unhappy and/or angry";

4. past relationships, such as, "If I saw a photograph of my partner and an old date I would feel unhappy"; and

5. indifference, such as, "If my partner were to accidentally call me by the wrong name, I would become furious."

The questionnaire items are presented as statements to which participants respond on a 9-point Likert scale that ranges from 1 "Absolutely false, disagree completely" to 9 "Absolutely true, agree completely" with a neutral midpoint. Seven items are positively valenced and their scores are reversed so that higher aggregate scores signify greater jealousy. The Cronbach's $\alpha$ value for the IJS was .93.

\section{STATISTICS}

The relative mean substitution method was used to manage the few missing values in the Likert scales (Raaijmakers, 1999). The relative mean substitution method involved calculating a participant's relative position in the dataset by dividing the mean of the participant's valid data by the mean of the valid data for the remainder of the participants. A missing value in an item was estimated by multiplying the aforementioned ratio by the mean of the valid data for the particular item.

The TRD variable was strongly positively skewed and the values were logarithmically transformed (Log-TRD) to normalize the distribution (Tabachnick \& Fidell, 2001).

PGS-33 Grief was the dependent variable and the four emotion-based personality predispositions were the independent variables in a 5-step hierarchical 
multiple regression analysis. Log-TRD was introduced at Step 1, DES Envy was introduced at Step 2, IJS Jealousy was introduced at Step 3, PFQ-2 Shame was introduced at Step 4, and PFQ-2 Guilt was introduced at Step 5. DES Envy was entered before IJS Jealousy and PFQ-2 Shame was entered before PFQ-2 Guilt because it was considered theoretically important to control jealousy for the variance due to envy and guilt for the variance due to shame, thereby obtaining measures of "pure" jealousy and "pure" guilt (Ferguson \& Crowley, 1997; Harder, 1995; Smith et al., 1988; Tangney, 1996). Envy and jealousy were entered before shame and guilt because the former were the problematic emotions of particular interest in the present study and for this reason they were given first preference in the statistical allocation of shared variance (Ferguson \& Stegge, 1998). SPSS for Windows version 14.0 was used for the statistical computations (SPSS, 2005).

\section{RESULTS}

The descriptive statistics for PGS-33 Grief, DES Envy, IJS Jealousy and PFQ-2 Shame and Guilt are presented in Table 1. The value for PGS-33 was similar to the values reported by Toedter et al. (2001). The DES individual item values and the total values for PFQ-2 Shame and Guilt, and IJS Jealousy were somewhat higher than those reported by Smith et al. (1999), Harder and Zalma (1990) and Mathes et al. (1982), respectively, but, nevertheless, they were within an SD of these values.

The zero-order correlation matrix for grief, Log-TRD, and the four problematic emotions is shown in Table 2. Log-TRD had a moderate negative correlation with grief $(r=-.36)$. There was a moderate correlation between envy and jealousy $(r=.43)$ and a large correlation between shame and guilt $(r=.67)$. Envy had a large correlation with shame $(r=.60)$ and a moderate correlation with

Table 1. Descriptive Statistics for Grief, Envy, Jealousy, Shame, and Guilt

\begin{tabular}{lrr}
\hline & $M$ & \multicolumn{1}{c}{$S D$} \\
\hline PGS-33 Grief & 109.8 & 23.09 \\
DES Envy & 22.0 & 8.14 \\
IJS Jealousy & 140.6 & 34.39 \\
PFQ-2 Shame & 18.2 & 6.35 \\
PFQ-2 Guilt & 12.7 & 4.52 \\
\hline
\end{tabular}

Note: $N=441$. DES = Dispositional Envy Scale, IJS = Interpersonal Jealousy Scale, PFQ-2 = Personal Feelings Questionnaire-2, PGS-33 = Perinatal Grief Scale-33. 
Table 2. Zero-Order Correlation Matrix for Grief, Log-TRD, Envy, Jealousy, Shame, and Guilt

\begin{tabular}{|c|c|c|c|c|c|c|}
\hline & Grief & Log-TRD & Envy & Jealousy & Shame & Guilt \\
\hline Grief & - & & & & & \\
\hline Log-TRD & $-.36 * \star \star$ & - & & & & \\
\hline Envy & $.44^{\star \star \star}$ & $-.12^{\star}$ & - & & & \\
\hline Jealousy & $.36^{\star \star \star}$ & $-.12^{\star \star}$ & $.43^{\star \star \star}$ & - & & \\
\hline Shame & $.48^{\star \star \star}$ & -.08 & $.60 * \star \star$ & $.43^{\star \star \star}$ & - & \\
\hline Guilt & $.51^{\star \star *}$ & -.04 & $.48^{\star \star \star}$ & $.32^{\star \star \star}$ & $.67^{\star \star \star}$ & - \\
\hline
\end{tabular}

Note: $N=441$. Log-TRD $=$ Log time lapse since most recent death.

${ }^{\star} p<.05,{ }^{\star *} p<.01,{ }^{\star \star *} p<.001$ (2-tailed).

guilt $(r=.48)$, whereas jealousy compared with envy had smaller though still moderate correlations with shame $(r=.43)$ and guilt $(r=.32)$.

Partialing out or statistically controlling for the variance due to the confounding emotion allowed for a more discriminating evaluation of the correlation of each problematic emotion with grief. In this regard, envy controlled for jealousy had a moderate correlation with grief $(r=.34)$, whereas jealousy controlled for envy had a small correlation with grief $(r=.21)$. There were small correlations between shame controlled for guilt and grief $(r=.21)$ and guilt controlled for shame and grief $(r=.29)$.

The result of the hierarchical multiple regression of grief on Log-TRD, envy, jealousy shame and guilt is shown in Table 3 . The multiple $R$-value was statistically significant at each step. Log-TRD explained $13 \%$ of the variance in grief $\left(R^{2}=.13, p<.001\right)$. Envy controlled for the variance due to Log-TRD explained a further $16 \%$ of the variance in grief $\left(\Delta R^{2}=.16, p<.001\right)$. Jealousy controlled for the variance due to Log-TRD and envy explained a further $3 \%$ of the variance in grief $\left(\Delta R^{2}=.03, p<.001\right)$. Shame controlled for the variance due to Log-TRD, envy and jealousy explained a further $5 \%$ of the variance in grief $\left(\Delta R^{2}=.05\right.$, $p<.001)$. Finally, guilt controlled for the variance due to Log-TRD, envy, jealousy and shame explained a further $6 \%$ of the variance in grief $\left(\Delta R^{2}=.06\right.$, $p<.001)$. The following variables made significant unique contributions to the variance in grief with all variables entered in the regression (see Table 3): $\log$-TRD $(\beta=-.31, p<.001)$, envy $(\beta=.14, p<.01)$, jealousy $(\beta=.11, p<.05)$ and guilt $(\beta=.32, p<.001)$. Shame did not make a statistically significant unique contribution to the variance in grief $(\beta=.10, p=.06)$. Overall, time lapse since the most recent child death and the four problematic emotion predispositions explained $43 \%$ of the variance in maternal grief following child bereavement. 
Table 3. Hierarchical Multiple Regression of Grief on Envy, Jealousy, Shame, and Guilt

\begin{tabular}{|c|c|c|c|c|}
\hline Variable & $B$ & SE B & $\beta$ & $t$ \\
\hline \multicolumn{5}{|l|}{ Step 1} \\
\hline Log-TRD & -12.95 & 1.59 & -.36 & $-8.16^{* * *}$ \\
\hline \multicolumn{5}{|l|}{ Step 2} \\
\hline Log-TRD & -11.25 & 1.44 & -.32 & $-7.80 * \star \star *$ \\
\hline Envy & 1.15 & .12 & .41 & $10.03^{* * *}$ \\
\hline \multicolumn{5}{|l|}{ Step 3} \\
\hline Log-TRD & -10.77 & 1.42 & -.30 & $-7.58 * \star \star$ \\
\hline Envy & .94 & .12 & .33 & $7.57^{\star \star \star}$ \\
\hline Jealousy & .12 & .03 & .18 & $4.03^{* * *}$ \\
\hline \multicolumn{5}{|l|}{ Step 4} \\
\hline Log-TRD & -10.86 & 1.37 & -.30 & $-7.94^{\star * \star}$ \\
\hline Envy & .51 & .14 & .18 & $3.67^{* * *}$ \\
\hline Jealousy & .08 & .03 & .11 & $2.62^{\star \star}$ \\
\hline Shame & 1.08 & .18 & .30 & $6.12^{\star \star \star}$ \\
\hline \multicolumn{5}{|l|}{ Step 5} \\
\hline Log-TRD & -11.10 & 1.31 & -.31 & $-8.50 * * *$ \\
\hline Envy & .40 & .13 & .14 & 2.96 ** \\
\hline Jealousy & .07 & .03 & .11 & $2.67^{\star \star}$ \\
\hline Shame & .38 & .20 & .10 & 1.90 \\
\hline Guilt & 1.66 & .25 & .32 & $6.56^{\star \star *}$ \\
\hline
\end{tabular}

Note: Step 1: $R=.36, F(1,439)=66.67, p<.001, R^{2}=.13$. Step $2: R=.54, F(2,438)=$ 91.21, $p<.001, R^{2}=.29, \Delta R^{2}=.16, F$ change $=100.62, p<.001$. Step $3: R=.56$, $F(3,437)=68.35, p<.001, R^{2}=.32, \Delta R^{2}=.03, F$ change $=16.27, p<.001$. Step $4: R=.61$, $F(4,436)=64.88, p<.001, R^{2}=.37, \Delta R^{2}=.05, F$ change $=37.41, p<.001$. Step $5: R=.66$, $F(5,435)=65.50, p<.001, R^{2}=.43, \Delta R^{2}=.06, F$ change $=42.98, p<.001$. Log-TRD $=$ Log time lapse since most recent death.

${ }^{*} p<.05,{ }^{* *} p<.01,{ }^{* * *} p<.001$ (2-tailed).

\section{DISCUSSION}

Personality envy- and jealousy-proneness were moderately correlated with maternal grief, and both emotions made statistically significant unique contributions to the variance in maternal grief, even though "when both emotions are present, they almost inevitably lose their separate identities" (Farber, 1976a, p. 41). Envy compared with jealousy had a stronger correlation with maternal grief and made a larger unique contribution to its variance. The moderate zero-order 
correlation of envy with grief persisted when envy was controlled for jealousy, whereas the moderate zero-order correlation between jealousy and grief was reduced to a small correlation when jealousy was controlled for envy. These partial correlation findings were not unexpected, since the present study confirmed previous research that has shown envy and jealousy covary (Smith et al., 1999) and because individuals are known to describe jealousy and envy in terms of jealousy, but to rarely describe jealousy in terms of envy (Smith et al., 1988).

Envy was second to chronic guilt in the magnitude of the unique contribution made by the problematic emotions to the variance in grief. The fact that dispositional envy was correlated with maternal grief following the death of a child was in keeping with mothers' perception that reproductive loss represents "failure" (Furman, 1978; Leon, 1992) and the notion that envy occurs "when the disadvantaged person has suffered a recent setback, when the advantaged person is similar on comparison-related attributes, and when the domain of comparison is important to the self' (Smith et al., 1999, pp. 1007-1008). Although not directly addressed in the present study, and perhaps an unlikely possibility, bereaved mothers may have been disconcerted by fear of envy of the dead (Foster, 1972), since "unresolved and unrecognized envy, often experienced in projection, is frequently a clinically important feature of persistent bereavement reactions" (Hobson, 1985, p. 128).

The fact that the Interpersonal Jealousy Scale (IJS) is a self-report measure of proneness to "romantic" jealousy (Mathes \& Severa, 1981), rather than other types of jealousy occasioned by the threat of loss to a rival in a non-romantic relationship (Bevan, 2004; Hansen, 1991; Parrott, 1991), is a potential shortcoming of the present study (White \& Mullen, 1989). However, even though self-report measures of jealousy, including the IJS, focus on romantic relationships (White \& Mullen, 1989), jealousy as a personality trait or disposition "should generalize across situations [and] items assessing dispositional jealousy attempt to sample 'jealousy' . . . in different domains, not just the romantic context" (White \& Mullen, 1989, p. 290).

The relation between jealousy and grief is not readily understood in terms of the mother's dyadic relationship with the dead child, since the presence of jealousy usually infers that a valued relationship is threatened by a real or imagined rival (White \& Mullen, 1989). There are, however, several plausible explanations for the positive correlation between proneness to jealousy and grief. First, the relationship between jealousy and grief may have been factitious because of a shared correlation with an unmeasured variable, such as an adult attachment style (Collins \& Read, 1990; Guerrero, 1998; Sharpsteen \& Kirkpatrick, 1997; Shaver \& Tancredy, 2001). Second, the measures of grief and jealousy may have captured the same primary emotions - fear, anger and/or sadness, which are commonplace in both grief (Bowlby, 1975, 1981) and jealousy (Hupka, 1984; Sharpsteen, 1991), particularly if the IJS lacked ecological validity in bereaved women. In any event, the face validity of the PGS-33 and IJS scale items and the 
small correlation between jealousy controlled for envy and grief suggest the questionnaires measured different constructs and that grief and jealousy are separate but related compound emotions or "passions" evoked by loss (Solomon, 1993). Third, grieving mothers' jealousy may have been aroused by their perception that the infant was in danger of being lost to an abstract rather than actual rival, such as a personification of death or a deity, since "when loved persons are not available to us and they are (thought or felt to be) available to others, their absence will tend to be experienced as 'loss to a rival"' (Neu, 1980, p. 428). The final and perhaps most cogent explanation for the correlation between jealousy and grief relates to the possibility that jealousy was evoked by the threat of loss in a situation of "high family boundary ambiguity" (Boss \& Greenberg, 1984; Hansen, 1991). According to Boss and Greenberg (1984), high family boundary ambiguity exists when a person in a valued relationship experiences the important other as being psychologically present but physically absent or, alternatively, psychologically absent but physically present. If the deceased child is psychologically present but physically absent in the mother's world, the threat of loss occasioned by this ambiguity may cause her to feel jealous (Hansen, 1991). Similarly, differences in gender roles and stereotypes may prompt a grieving mother to perceive her husband or partner as physically present but psychologically absent (Doka \& Martin, 2001), thereby creating an ambiguous state of affairs that poses a threat to her relationship that she may describe as jealousy (Hansen, 1991).

Personality shame- and guilt-proneness had respective moderate and large correlations with grief and, notably, chronic guilt was the problematic emotion that made the largest unique contribution to the variance in maternal grief. The PFQ-2 measure of chronic guilt-proneness has been correlated with psychological symptoms (Bybee \& Quiles, 1998; Harder, 1995) and may be qualitatively similar to the self-reviling guilt that Freud (1961/1930) and others (Buber, 1957; Lewis, 1979; Prosen, Clark, Harrow, \& Fawcett, 1983) have associated with psychopathology, and Cullberg (1971) and others (Miles \& Demi, 1986) have related to maternal grief. The relationship of (PFQ-2) chronic shame- and guiltproneness to grief in this study was similar to that reported in more depth in a study of perinatally bereaved Australian mothers (Barr, 2004), thereby suggesting the relation of chronic shame- and guilt-proneness to maternal grief may be generalizable, at least across similar cultures. The theoretical possibility that guilt "fused" with shame (Lewis, 1971; Tangney et al., 1995), rather than guilt per se (Bybee \& Quiles, 1998), might determine the correlation with maternal grief was offset by statistically controlling guilt for shame in the partial correlation and hierarchical multiple regression analyses (Ferguson \& Stegge, 1998; Harder, 1995). On the downside, the fact that shame did not make a unique contribution to the variance in maternal grief may have been an unwanted consequence of the partialing procedure, whereby shame's shared variance with grief was allocated to guilt and/or envy (Ferguson \& Stegge, 1998). 
There were potential disadvantages to the predominantly online method of research used in this study, including the exclusion of participants who were not computer literate, the possibility that some participants may have made multiple submissions or responded unthoughtfully or insincerely, and the substantial participant drop-out rate (Reips, 2002). In addition, the self-report questionnaire nature of the study meant that it was susceptible to errors from respondent tendencies to agree, be indecisive, or prefer extreme responses (Baldwin, 2000; Rust \& Golombok, 1999; Stone et al., 2000). Finally, participants may have experienced difficulty identifying, distinguishing, and/or quantifying the emotions under examination (Barrett \& Campos, 1987; White \& Mullen, 1989). The foregoing concerns and the fact that the study participants were a convenience sample of mostly well-educated computer literate European-American women in their 30s suggest caution should be exercised in extrapolating the findings to other populations of bereaved mothers.

Despite the preceding caveats, dispositional envy and jealousy, as well as shame and guilt, showed significant correlations with maternal grief. Although the cross-sectional and correlational nature of the study precludes any definite conclusion regarding direction of causality, the inherently stable nature of personality traits make it more likely that maternal grief was aggravated by one or more dispositional problematic emotion rather than proposing a causal relationship in the opposite direction (Ekman \& Davidson, 1994).

The vignettes presented in the introduction suggest that bereaved mothers may not be aware that one or more problematic emotion attends their grief and thus not be in a position to identify, express, reframe and assimilate these emotions in a way that is functional, or at least neutral, and not pathogenic (Barrett \& Campos, 1987; Raphael et al., 2001; Tangney \& Salovey, 1999). Although the value of emotional disclosure in the amelioration of grief is arguable (Archer, 1999), particularly with regard to the value of expressing negative emotions (Bonanno, 2001), one necessary but not sufficient condition for effective counseling should be the correct identification of each troublesome emotion, not withstanding that shame and envy, in particular, may be difficult to identify in everyday discourse and "analyze" in psychotherapy (Bourne, 1968; Farber, 1976a; Foster, 1972; Lewis, 1971; Retzinger, 1995).

In principle, emotion-focused therapy (Greenberg \& Paivio, 1993) should offer mothers the wherewithal to:

1. ameliorate envy by discouraging downward social comparisons and encouraging acceptance of unavoidable individual differences in advantage (Anderson, 2002), thereby "giving up the sense of being victimized by fate" (Lazarus \& Lazarus, 1994, p. 30);

2. align jealousy with the notion of vigilance and the important evolutionary task of "jealously" guarding self-defining relationships (White \& Mullen, 1989); 
3. transform self-denigrating shame into a search for personal authenticity (Lynd, 1958); and

4. disentangle behavior-based guilt from character-based shame (JanoffBulman, 1979; Weiner, 1986) and learn that guilt may be an empathyrelated prosocial emotion that motivates individuals to maintain or restore supportive interpersonal relationships (Baumeister, Stillwell, \& Heatherton, 1994; Tangney et al., 1995).

If bereaved mothers were to become more aware of their negative emotionbased personality predispositions, understand how these traits may adversely affect their grief, and learn how to render them more functional and healthful, they may come to realize that:

Our lives do not simply fall apart, they collapse in structured ways, and the fault lines are marked by our concepts. Our ways of understanding and describing our psychological states often reveal (and sometimes limit) the potentials in those states themselves, the potentials for both development and disorder (Neu, 1980, p. 428).

\section{REFERENCES}

Anderson, R. E. (2002). Envy and jealousy. American Journal of Psychotherapy, 56, 455-479.

Archer, J. (1999). The nature of grief: The evolution and psychology of reactions to loss. London, England: Routledge.

Baldwin, W. (2000). Information no one else knows: The value of self-report. In A. A. Stone, J. S. Turkkan, C. A. Bachrach, J. B. Jobe, H. S. Kurtzman \& V. S. Cain (Eds.), The science of self-report: Implications for research and practice (pp. 3-7). Mahwah, NJ: Erlbaum.

Barr, P. (2004). Guilt- and shame-proneness and the grief of perinatal bereavement. Psychology and Psychotherapy: Theory, Research and Practice, 77, 493-510.

Barrett, K. C., \& Campos, J. J. (1987). Perspectives on emotional development II: A functionalist approach to emotions. In J. D. Osofsky (Ed.), Handbook of infant development (2nd ed., pp. 555-578). Oxford, England: Wiley.

Baumeister, R. F., Stillwell, A. M., \& Heatherton, T. F. (1994). Guilt: An interpersonal approach. Psychological Bulletin, 115, 243-267.

Berke, J. H. (1987). Shame and envy. In D. L. Nathanson (Ed.), The many faces of shame (pp. 318-334). New York: Guilford Press.

Bevan, J. L. (2004). Toward a broader conceptualization of jealousy in close relationships: Two exploratory studies. Communication Studies, 55, 14-28.

Birnbaum, M. H. (2004). Human research and data collection via the Internet. Annual Review of Psychology, 55, 803-832.

Bonanno, G. A. (2001). Grief and emotion: A social-functional perspective. In M. S. Stroebe, R. O. Hansson, W. Stroebe, \& H. Schut (Eds.), Handbook of bereavement research: Consequences, coping, and care (pp. 493-515). Washington, DC: American Psychological Association. 
Borg, S., \& Lasker, J. (1989). When pregnancy fails: Families coping with miscarriage, ectopic pregnancy, stillbirth, and infant death (Rev. ed.). New York: Bantam Books.

Boss, P., \& Greenberg, J. (1984). Family boundary ambiguity: A new variable in family stress theory. Family Process, 23, 535-546.

Bourne, S. (1968). The psychological effects of stillbirths on women and their doctors. Journal of the Royal College of General Practitioners, 16, 103-112.

Bowlby, J. (1975). Attachment and loss, Volume II. Separation: Anxiety and anger. Camberwell, Victoria, Australia: Penguin Books.

Bowlby, J. (1981). Attachment and loss, Volume III. Loss: Sadness and depression. Camberwell, Victoria, Australia: Penguin Books.

Buber, M. (1957). Guilt and guilt feelings. Psychiatry, 20, 114-129.

Bybee, J., \& Quiles, Z. N. (1998). Guilt and mental health. In J. Bybee (Ed.), Guilt and children (pp. 269-291). San Diego, CA: Academic Press.

Collins, N. L., \& Read, S. J. (1990). Adult attachment, working models, and relationship quality in dating couples. Journal of Personality and Social Psychology, 58, 644-663.

Cullberg, J. (1971). Mental reactions of women to perinatal death. Paper presented at the Psychosomatic Medicine in Obstetrics and Gynaecology, Third International Congress, London, England.

Doka, K. J., \& Martin, T. (2001). Take it like a man: Masculine response to loss. In D. A. Lund (Ed.), Men coping with grief (pp. 37-47). Amityville, NY: Baywood.

Ekman, P., \& Davidson, R. J. (Eds.). (1994). The nature of emotion: Fundamental questions. Oxford, England: Oxford University Press.

Farber, L. H. (1976a). Faces of envy. In Lying, despair, jealousy, envy, sex, suicide, drugs, and the good life (pp. 35-45). New York: Basic Books.

Farber, L. H. (1976b). On jealousy. In Lying, despair, jealousy, envy, sex, suicide, drugs, and the good life (pp. 180-202). New York: Basic Books.

Ferguson, T. J., \& Crowley, S. L. (1997). Measure for measure: A multitrait-multimethod analysis of guilt and shame. Journal of Personality Assessment, 69, 425-441.

Ferguson, T. J., \& Stegge, H. (1998). Measuring guilt in children: A rose by any other name still has thorns. In J. Bybee (Ed.), Guilt and children (pp. 19-74). San Diego, CA: Academic Press.

Foster, G. M. (1972). The anatomy of envy: A study of symbolic behavior. Current Anthropology, 13, 165-202.

Freud, S. (1961/1930). Civilization and its discontents. In J. Strachey (Ed.), The standard edition of the complete psychological works of Sigmund Freud (Vol. 21, pp. 57-146). London, England: Hogarth Press. (Original work published 1930.)

Furman, E. (1978). The death of a newborn: Care of the parents. Birth and the Family Journal, 5, 214-218.

Furman, E. (1996). On motherhood. Journal of the American Psychoanalytic Association, 44(Suppl.), 429-447.

Greenberg, L. S., \& Paivio, S. C. (1993). Working with emotions in psychotherapy. New York: Guilford Press.

Guerrero, L. K. (1998). Attachment-style differences in the experience and expression of romantic jealousy. Personal Relationships, 5, 273-291.

Hansen, G. L. (1991). Jealousy: Its conceptualization, measurement, and integration with family stress theory. In P. Salovey (Ed.), The psychology of jealousy and envy (pp. 211-230). New York: Guilford Press. 
Harder, D. W. (1995). Shame and guilt assessment and relationships of shame- and guilt-proneness to psychopathology. In J. P. Tangney \& K. W. Fischer (Eds.), Selfconscious emotions: The psychology of shame, guilt, embarrassment, and pride (pp. 368-392). New York: Guilford Press.

Harder, D. W., \& Greenwald, D. F. (2000). The psychotherapy of shame-related pathology from an evolutionary perspective. In P. Gilbert \& K. G. Bailey (Eds.), Genes on the couch: Explorations in evolutionary psychotherapy (pp. 304-329). Philadelphia, PA: Brunner-Routledge.

Harder, D. W., \& Lewis, S. J. (1987). The assessment of shame and guilt. In C. D. Spielberger \& J. N. Butcher (Eds.), Advances in personality assessment (Vol. 6, pp. 89-114). Hillsdale, NJ: Erlbaum.

Harder, D. W., \& Zalma, A. (1990). Two promising shame and guilt scales: A construct validity comparison. Journal of Personality Assessment, 55, 729-745.

Hobson, R. F. (1985). Forms of feeling: The heart of psychotherapy. London, England: Tavistock Publications Ltd.

Hupka, R. B. (1984). Jealousy: Compound emotion or label for a particular situation. Motivation \& Emotion, 8, 141-155.

Janoff-Bulman, R. (1979). Characterological versus behavioral self-blame: Inquiries into depression and rape. Journal of Personality and Social Psychology, 37, 1798-1809.

Kohner, N., \& Henley, A. (2001). When a baby dies: The experience of late miscarriage, stillbirth and neonatal death. London, England: Routledge.

Kugler, K., \& Jones, W. H. (1992). On conceptualizing and assessing guilt. Journal of Personality and Social Psychology, 62, 318-327.

Lasker, J. N., \& Toedter, L. J. (2000). Predicting outcomes after pregnancy loss: Results from studies using the Perinatal Grief Scale. Illness, Crisis \& Loss, 8, 350-372.

Lazarus, R. S., \& Lazarus, B. N. (1994). Passion and reason: Making sense of our emotions. Oxford, England: Oxford University Press.

Leon, I. G. (1992). The psychoanalytic conceptualization of perinatal loss: A multidimensional model. American Journal of Psychiatry, 149, 1464-1472.

Lewis, H. B. (1971). Shame and guilt in neurosis. New York: International Universities Press.

Lewis, H. B. (1979). Guilt in obsession and paranoia. In C. E. Izard (Ed.), Emotions in personality and psychopathology (pp. 399-414). New York: Plenum Press.

Lewis, H. B. (1987). The role of shame in depression over the life span. In H. B. Lewis (Ed.), The role of shame in symptom formation (pp. 29-50). Hillsdale, NJ: Erlbaum.

Lynd, H. M. (1958). On shame and the search for identity. New York: Science Editions.

Malatesta, C. Z., \& Wilson, A. (1988). Emotion cognition interaction in personality development: A discrete emotions, functionalist analysis. British Journal of Social Psychology, 27, 91-112.

Mathes, E. W., Phillips, J. T., Skowran, J., \& Dick, W. E. (1982). Behavioral correlates of the Interpersonal Jealousy Scale. Educational and Psychological Measurement, 42, 1227-1231.

Mathes, E. W., \& Severa, N. (1981). Jealousy, romantic love, and liking: Theoretical considerations and preliminary scale development. Psychological Reports, 49, 23-31.

Miles, M. S., \& Demi, A. S. (1986). Guilt in bereaved parents. In T. A. Rando (Ed.), Parental loss of a child (pp. 97-118). Champaign, IL: Research Press. 
Nathanson, D. L. (Ed.). (1987). The many faces of shame. New York: Guilford Press.

Neu, J. (1980). Jealous thoughts. In A. O. Rorty (Ed.), Explaining emotions (pp. 425-463). Berkeley, CA: University of California Press.

Parrott, W. G. (1991). The emotional experiences of envy and jealousy. In P. Salovey (Ed.), The psychology of jealousy and envy (pp. 3-30). New York: Guilford Press.

Parrott, W. G., \& Smith, R. H. (1993). Distinguishing the experiences of envy and jealousy. Journal of Personality \& Social Psychology, 64, 906-920.

Potvin, L., Lasker, J., \& Toedter, L. (1989). Measuring grief: A short version of the Perinatal Grief Scale. Journal of Psychopathology and Behavioral Assessment, 11, 29-45.

Prosen, M., Clark, D. C., Harrow, M., \& Fawcett, J. (1983). Guilt and conscience in major depressive disorders. American Journal of Psychiatry, 140, 839-844.

Raaijmakers, Q. A. W. (1999). Effectiveness of different missing data treatments in surveys with Likert-type data: Introducing the relative mean substitution approach. Educational and Psychological Measurement, 59, 725-748.

Raphael, B., Minkov, C., \& Dobson, M. (2001). Psychotherapeutic and pharmacological intervention for bereaved persons. In M. S. Stroebe, R. O. Hansson, W. Stroebe, \& H. Schut (Eds.), Handbook of bereavement research: Consequences, coping, and care (pp. 587-612). Washington, DC: American Psychological Association.

Reips, U.-D. (2002). Standards for Internet-based experimenting. Experimental Psychology, 49, 243-256.

Retzinger, S. (1995). Identifying shame and anger in discourse. American Behavioral Scientist, 38, 1104-1113.

Rust, J., \& Golombok, S. (1999). Modern psychometrics: The science of psychological assessment (2nd ed.). London, England: Routledge.

Salovey, P.(Ed.). (1991). The psychology of jealousy and envy. New York: Guilford Press.

Sharpsteen, D. J. (1991). The organization of jealousy knowledge: Romantic jealousy as a blended emotion. In P. Salovey (Ed.), The psychology of jealousy and envy (pp. 31-51). New York: Guilford Press.

Sharpsteen, D. J., \& Kirkpatrick, L. A. (1997). Romantic jealousy and adult romantic attachment. Journal of Personality and Social Psychology, 72, 627-640.

Shaver, P. R., \& Tancredy, C. M. (2001). Emotion, attachment, and bereavement: A conceptual commentary. In M. S. Stroebe, R. O. Hansson, W. Stroebe, \& H. Schut (Eds.), Handbook of bereavement research: Consequences, coping, and care (pp. 63-88). Washington, DC: American Psychological Association.

Smith, R. H. (1991). Envy and the sense of injustice. In P. Salovey (Ed.), The psychology of jealousy and envy (pp. 79-99). New York: Guilford Press.

Smith, R. H., Kim, S. H., \& Parrott, W. G. (1988). Envy and jealousy semantic problems and experiential distinctions. Personality \& Social Psychology Bulletin, 14, 401-409.

Smith, R. H., Parrott, W. G., Diener, E. F., Hoyle, R. H., \& Kim, S. H. (1999). Dispositional envy. Personality \& Social Psychology Bulletin, 25, 1007-1020.

Solomon, R. C. (1993). The passions: Emotions and the meaning of life. Indianapolis, IN: Hackett Publishing Company.

SPSS. (2005). SPSS for Windows (Version 14.0). Chicago, IL: SPSS Inc.

Stone, A. A., Turkkan, J. S., Bachrach, C. A., Jobe, J. B., Kurtzman, H. S., \& Cain, V. S. (Eds.). (2000). The science of self-report: Implications for research and practice. Mahwah, NJ: Erlbaum. 
Sullivan, H. S. (1953). The interpersonal theory of psychiatry. In H. S. Perry \& M. L. Gawel (Eds.). New York: Norton.

Tabachnick, B. G., \& Fidell, L. S. (2001). Using multivariate statistics (4th ed.). Sydney, Australia: Allyn and Bacon.

Tangney, J. P. (1995). Shame and guilt in interpersonal relationships. In J. P. Tangney \& K. W. Fischer (Eds.), Self-conscious emotions: The psychology of shame, guilt, embarrassment, and pride (pp. 114-139). New York: Guilford Press.

Tangney, J. P. (1996). Conceptual and methodological issues in the assessment of shame and guilt. Behaviour Research and Therapy, 34, 741-754.

Tangney, J. P., Burggraf, S. A., \& Wagner, P. E. (1995). Shame-proneness, guilt-proneness, and psychological symptoms. In J. P. Tangney \& K. W. Fischer (Eds.), Selfconscious emotions: The psychology of shame, guilt, embarrassment, and pride (pp. 343-367). New York: Guilford Press.

Tangney, J. P., \& Dearing, R. L. (2002). Shame and guilt. New York: Guilford Press.

Tangney, J. P., \& Salovey, P. (1999). Problematic social emotions: Shame, guilt, jealousy, and envy. In R. M. Kowalski \& M. R. Leary (Eds.), The social psychology of emotional and behavioral problems: Interfaces of social and clinical psychology (pp. 167-195). Washington, DC: American Psychological Association.

Toedter, L. J., Lasker, J. N., \& Alhadeff, J. M. (1988). The Perinatal Grief Scale: Development and initial validation. American Journal of Orthopsychiatry, 58, 435-449.

Toedter, L. J., Lasker, J. N., \& Janssen, H. J. (2001). International comparison of studies using the Perinatal Grief Scale: A decade of research on pregnancy loss. Death Studies, 25, 205-228.

Weiner, B. (1986). An attributional theory of motivation and emotion. New York: Springer-Verlag.

White, G. L., \& Mullen, P. E. (1989). Jealousy: Theory, research, and clinical strategies. New York: Guilford Press.

Direct reprint requests to:

Dr. Peter Barr

Department of Neonatology

The Children's Hospital at Westmead

Locked Bag 4001

Westmead, NSW, 2145

Australia

e-mail: peter@chw.edu.au 